\title{
CHILDHOOD AND LITERACY (A CRITICAL STUDYOF MEDIA EDUCATION AS CONTEMPORARY CULTURE)
}

\author{
Muhammad Nafi Annury \\ UIN WALISONGO SEMARANG \\ nafiannury@gmail.com
}

\begin{abstract}
Childhood is the phase of where the human beginning to learn about its surrounding obviously. This phase needs more attention from us as parent however, to make sure that our children keep in the right path of their development. Therefore, the development of ICT brings many consequences in every aspect of our life; and this condition has influenced too toward children development anyway. Based on this phenomenon, the writer would like to introduce some problems relate with childhood and literacy. The literacy of using the media education, therefore, teacher and parents should be concerned about it to the children. Teacher and parents however, they have to give better guidance to children relate with may information and ICT which are used in the classroom or at home. Children should be given better understanding by teacher and parents everytime they need information. Some experts say that media can give positive and negative effect obviously. Thus, the writer hopes that may give any review by this article.
\end{abstract}

Keywords: childhood, literacy, education 


\section{INTRODUCTION}

Naturally, human being needs to communicate with others, people needs a means of communication which is called language. Therefore, language is one of the most important things in human life. By language, people can express his ideas and wish to other people such as when he needs help. Brown (2000) argues that language is a system of arbitrary, conventionalized vocal, written, or gestural symbols that enable members of a given community to communicate intelligibly with other. It is important for them to build communication and interaction with other especially. Language as a means of communication is a system or arbitrary symbol by which human's being cooperate and interact.

Moreover, by using language people can express their feelings, ideas, throughout and attitude; toward life and also wishes to other people. It means that without language it is hard for people can cooperate with, and to get along with other. Through a language, children will improve their social skill with others. The competency of a social skill in their environment is started by mastering language. Children may easily build some relationships with others if they have already had communication skills as well.

The language competence for children in the $4^{\text {th }}-5^{\text {th }}$ years old is in the middle phase of language development expressively. It means that children are able to express what they want, refusing their ideas by using verbal sentence as a means of communication. Children on these ages may utter some words, combine some words become meaningful sentences, however Hurlock (1989) says "the ability of communication on pre-school children with others are still in the low level. There is some vocabulary that should be mastered to be able to use for as well". In some extend, the use of vocabulary for communication is the key of succeeding the better of communication itself. One of the factors which are influencing the process of communication is the vocabulary mastery.

Nowadays, people cannot be lived with technology. Electricity and communication devices are means for people communicating with others. People tend to be not having self-confidence without their gadgets actually. The improvement of media in this era has influ- 
enced the way how people live actually. This can be seen that the use media cannot be separated from our daily life. The internet, television, computer and cell phones are the examples of devices which we have already had surround us.

The Indonesian Minister of Communication and Information, Muhammad Nuh urges for the mass media both written and electronic to concern seriously about the reporting on children problems. As we know that, recently, there is limited portion exposed to the information, frequency and content which supporting children needs toward their future. It cannot be ignored from our concern anyway (SinarHarapan, 15 April 2009).

Furthermore, Arsyad (2002:169) says that the use of teaching media may cope with their senses, time and space; also may offer the equality of their experiences to the children about situations surrounding them. Sudjana and Rivai (1999) say that the benefit ot teaching media; it will create teaching-learning process more fun and enjoyable; so that it motivates students not only to listen teacher's explanation, but they more influenced in observing, doing, and demonstrating, role-playing, etc.

The use of me is not merely for fun but also, it can be used for media education. We may see that ICT as media education has applied in education institution; such as from play group until university. Teachers and students are already having good perspective of the existence from the ICT. Teachers and students need to use it for better quality in understanding about certain subject matters after all. Here, they sometimes face many problems when using the ICT. The problems come up while they do not have understanding or illiterate towards something which contain inside of ICT's usage. As we know that the media of education which comes from the ICT device has their own strength and weaknesses.

Talking about ICT as media education Buckingham said that there are three dimensions consists in the use of media education. Firstly, like many advocates of media education; it is lack of progress we seem to have made among educational policy-makers in recent years. Where students are free to choose it - and teachers free to offer it - media education continues to expand a quite alarming rate. Secondly, among academics there has been a fourishing of esoteric 
political rhetoric and an increasing taste for utopian fantasies about educational change. The third, there are some fact that teachers of media education still seem to be insufficiently recognized and supported. Despite the generally inhospitable climate, there is a great deal of excellent work being done in the field by highly dedicated teachers and committed students (Tapscott, 1989).

Our approach to the media education is bound to depend upon the assumptions we make about the relationships between media and their audiences. Nowadays, children are surrounded by the various kinds of media actually. The media plays the important roles in educational sector; however, it needs people wisdom when in the usage. There are two valuable lessons to be learned here; they are as follows: first, one of the significant roles that family has or can have as mediators of the televisual experience between the media sources and the younger members of the family - this theme is now well known in the psychology of media, but it always needs repeating. Secondly, is the native nature of the Tarpley (2009: 4) viewing experience and how media provides a source that can challenge us? That depends on us whether we use it well or badly, in our roles as parents and educators, it is up to us to teach and tell others how to do so.

Some experts argue this theme by looking at six primary new technologies: digital television; video on demand, including subscription video on demand; interactive video on demand; interactive program guides; personal video recorders; interactive and enhanced television and the internet. It is clear for us that the various kind of technologies not standing alone from one and others. We may choose which one is the most appropriate; depending on the situation and condition anyway. Children eager to learn something new; they should be facilitated by the good media as well. By this, teachers and parents should pay their attentions and focus in educating the children.

Children as young learners must be protected from the media abused. There are many factors why protecting children as one of the focuses in doing teaching and learning process. Children when they stay at their houses; so the parents must facilitate them with pa- 
rental guidance while they watching audio-visual (television, video recorder). It is the same when they study at their schools; so that teachers must be responsible too. Children having different their own styles in consuming media as experienced. We should consider to all these dynamics point of view.

It is possible to identify two contrasting views of the relationship between children and media, both of which have been influential in popular and academic debate. On the one hand, there is the idea that childhood as we know it is dying or disappearing, and that the media are now a force of deliberation that is more open, more democratic, and socially aware than their parents' generation. In some ways, these two views are diametrically opposed, not least in their underlying assumptions about childhood; yet there are also some striking similarities between them.

However, cchildhood is the stage of children development which started from the age zero until five years old. It usually so called by the golden age. Therefore, there are many kinds of media which surrounding children in this global era. The existence of media may give well or bad influenced the children. Parents and teachers should pay their attention more toward the effects that appear in the children future.

Consequently, parents and teachers' literacy of media are needed to overcome the problem that rose due to the children development psychologically. There are two valuable lessons here; they are that the members of families can be as mediators of visual experience between media sources and the young family members. Moreover, the family members play the important roles in describing the television programs carefully.

In the order to focus on the study, there are some problems revealed from this topic above; how the media literacy is influenced the childhood, and what is the implication of media literacy this global era? 


\section{BACKGROUND LITERATURE}

\section{Childhood}

Childhood is the age span ranging from birth to adolescence. In developmental psychology, childhood is divided up into the developmental stages of toddlerhood (learning to walk), early childhood (play age), middle childhood (school age), and adolescence (puberty through post-puberty). The term childhood is non-specific and can imply a varying range of years in human development. Developmentally, it refers to the period between infancy and adulthood. In common terms, childhood is considered to start from birth. Some consider that childhood, as a concept of play and innocence, ends at adolescence. In many countries, there is an age of majority when childhood officially ends and a person legally becomes an adult. The age ranges anywhere from 15 to 21, with 18 being the most common. In some extends, the developmental of the childhood can be stated as follows:

1. a. Early childhood.

It is the first step of children begins to speak and taking step without parents independently. The term childhood is nonspecific and can imply a varying range of years in human development. Developmentally, it refers to the period between infancy and adulthood. In common terms, childhood is considered to start from birth. Some consider that childhood, as a concept of play and innocence, ends at adolescence. In many countries, there is an age of majority when childhood officially ends and a person legally becomes an adult. The age ranges anywhere from 15 to 21 , with 18 being the most common.

2. b. Middle childhood.

Middle childhood begins at around age seven or eight, approximating primary school age and ends around puberty, which typically marks the beginning of adolescence.

3. c. Adolescence

Adolescence is usually determined by the onset of puberty. However, puberty may also begin in preadolescents. The end of adolescence and the beginning of adulthood varies by country and by function, and even within a single nation-state or culture 
there may be different ages at which an individual is considered to be (chronologically and the legally) mature enough to be entrusted by society with certain tasks.

Furthermore, there are two major points that should be concerned about the definition of children itself. Firstly, there is the Convention of Children Right (Konvensi Hak Anak) United Nation Organization (UN) on the November $20^{\text {th }}, 1989$; which has been applied by Indonesian Government on 1990. The content of this convention is the rules of children protection; this makes Indonesian Government has to follow the agreement up and fulfill the children's right as well. As it implementation, the government, thus, legalizing Undang Undang Republik Indonesia No 23 Tahun 2002 about Perlindungan Anak (UU PA).

As the description above, the development of the childhood is therefore, being our attention to be concerned well. Children cannot be independent ones yet; they still develop in the future. However, the environment surrounding us gives the major impact due to the children development. The environment, actually, consists of two major points, such as the inner (family) and the outside one. Both environments, however, children will develop their knowledge gradually. They learn everything surrounds them; try to speak, having interaction with someone else, understanding what they see, listen and touching what they find in front of them for instances. This is all the process of learning for. By this, the development of children self-behavior would be improved naturally.

Thing that we should know, however, the enlightenment philosophers based their ideas their ideas on their beliefs that man is the nature good and pure, and that individual differences can be attributed to environmental circumstances. The environment could be positive, stimulating influences on children, but could also have a negative and destructive effect.

\section{Media}

\subsection{The Definition of Media}

The word media derives from the Latin language which means 
medium, device, or in the middle. In the Arabic language media is a kind of tool for sending messages. Gerlach \& Ely (2008) say that the human, materials, or any circumstances which develop some conditions that make students are able to obtain knowledge, skill, and or attitude, basically. We might say that teacher, text books, and the school environment, for instances, which so called media. Especially, the term media in the teaching and learning process tends to be defined as media. Particularly, the termination of media in teaching and learning process in the classroom can be said as graphical devices, photographic or electronic devices to get, process and or to reconstruct the information both visual or verbally.

Furthermore, according to KBBI (The Indonesian Dictionary Encyclopedia) the word "media" such as newspaper, magazine, radio, television, poster and banner. Yet the media has some meaning such as: tool of communication, a mediator or which lies between two parties or groups. Whereas the word "massa" it refers to the sum of accounts; like a large group of people. So, when we may combine these both words to become a media and an official channel as a tool for broadcasting news and information for whole people.

From this notion of mass media; it might be explained that mass media is a kind of communication which addressed to scattered sum people, heterogonous and anonymous through printed media or electronic one; so that the original message of information can be achieved at the same time accurately.

Actually, the sum of recipients of information at the same time is not important here. However, Abbot (1998) says "the communicator is a social organization capable or reproducing the message and sending it simultaneously to large number of people who partially separated". Whereas, there are two kinds of mass media, such as: (1) Printed media; newspapers, magazines, and books ones. (2) Electronic media; radio, television, movies and internet also the cell phone.

Media are necessary in order to have efficiency and the effectiveness in teaching learning. Based on the Oxford Learner's Pocket Dictionary (2000), medium (plural media) is something which is 
used for a particular person. In this case, however, audiovisual aids and teaching material are other terms of media that are generally used in teaching-learning process.

Media will be so useful if they are used carefully and creatively prepared by the teachers, and they are used effectively to support the presentation of the lessons during the teaching and learning process. This leads to the conclusion that use of such kinds media is needed for children development. Sadiman states that instructional media for the teaching learning process especially in Indonesia can be clarified into four categories; they are stated below:

4. Games and simulation: word, puzzle and role playing.

5. Visual media which is media that can be seen and the function of visual media; distributing the message from the source to the receiver.

6. Audio media are different from the visual in common as audio that connected with one of the five senses that are ears that can hear something produced by sound. What is mean by the audio media here is the media that useful indeed.

7. Audio-visual media is media that useful because of their sound and picture. The examples are: TV and video recorder which being turned on then producing picture as well. 8 .

\subsubsection{Features of Teaching Media}

There are some general features of teaching media; they are as follows:

9. Teaching media are kinds hardware; something that can be seen, heard, touched by five senses.

10. Teaching media is software: lesson that will be delivered to students

11. Stressing of teaching media is on visual and audio

12. Teaching media is teaching aid both in or out of classroom

13. Teaching media is used for communicating and interacting between teacher and students in teaching process.

14. Teaching media can be used in mass (e.g. radio and TV), large group and the small one (e.g. film, video, OHP), or individual (e.g. module, computer, video recorder). 
15. Attitude, organization, strategy and the management are related to applying particular study.

From the explanation above, teaching media has some advantages for improving students' interest and raising students' enthusiasm in their learning process, obviously. Teacher may facilitate his students by applying the appropriate media as the explanation above. Applying media in teaching-learning process in the classroom has become a crucial requirement nowadays. We can see that there are many theories that delivered by the experts about the important of media.

\subsubsection{Types of Media}

According to Hamalik cited by Asnawir 2002), there four classifications of teaching media:

16. Visual media: filmstrip, transparency, micro projection, bulletin board, pictures, illustration, chart, graphic, poster, map and the globe.

17. Audited media: phonograph record, electric transcript, radio and recorder.

18. Audio visual media: film, TV, and three dimensional figures.

19. Dramatization, role play and sociodrama.

Moreover, Gerlach and Ely (cited by Arsyad, 2003:6) states there are three major kinds of media:

1. Fixative Property

This feature describes the ability of media in recording, saving, maintaining, and reconstructing current events or subjects. Events or objects can be rearranged by using media such as photography, video tape, camera, computer and film. The object that is recorded using camera or video recorder can be produced easily whenever needed. With this property, media may be recording of event or object occur in the particular time is transported along that time.

2. Manipulative Property

Transformation of the event or object is possible because 
media has manipulative property. Event that consumes several times can be played in front of students in two or three minutes using time-lapse recording. Besides that, the event can be also played slowly in the time showing the video recording. In addition, the event object through editing the result of recording can save the time.

3. Distributive Property

Distributive property of media may the object or event transported room and the even can be served to a number of students by stimulus to same experience in the same time. Recently distribution of media is not only use in class or classes of school in the particular region but also in all places demanded along the time. The information consistency that was recorded is as same as the original.

From the explanation above, we realize that media has some properties. It can record an event in particular time (Fixative Property). Besides, media can be played and edited (Manipulate Property). Finally, it can be distributed to other places and produced repeatedly as same as the original (Distributive Property).

\subsubsection{The Function of Media}

Media in the classroom are appropriate for triggering ideas; making difficult subjects are easy to understand, and holding for attention on important ideas. It should lead students to remember the ideas easily; and they also become influencing with it. Students should know about the function of media.

According to Levie and Lentz (cited from Arsyad, 2003: 16), there are four function of teaching media:

1. Attention Function

Media can attract students' attention to concentrate on lessons related to visual meaning showed. Sometimes, in the first lesson students are not interested in lesson materials. So, they do not pay attention on the lesson.

2. Affective Function

This function can be seen from students' interest when they learn or read pictured text. Picture or visual sign can en- 
dow students' attitude. Working with parents is as important as working with children. Barnados (2010) states 'A quality childcare service will value parents as the main career and education of child'. This is the key element to providing quality in early year's services and often an aspect that practitioners may shy away from. However, this is a vital area and should not be neglected. Engagement with families in the early years is the key to children's holistic development. The relationshipsthat surround a child have a great impact on their life.

Firstly, if the child sees a positive, trusting relationships they see around them (Keyser, 2006). Parents and practitioners can work together to create continuity between home and service, for example, adapting similar behavior management so the child is not too confused. When practitioners and parents communicate information to each other, the pactitioners can learn how he is at home and the parent learns how he is in the service. They have a fuller picture of the child's learning (Drapper \& Duffy, 2006). Current research and policies have a highlited the large impact on the child's development than the mother's occupation, own level of literacy or education (Wheeler \& Connor, 2009).

Correspondingly, a recent report published, confirmed that the home learning environment had the greatest impact on children's development and made the most difference in the later academic success of the child. Early years practitioners can use their knowledge to support parents in providing a good quality environment. By telling how important it is and may be giving them books or tips on how to get the most out of them. This can only happen if high levels of engagement with families are occurring. Siolta's Standard is on parents and families and it emphasizes the importance of having a proactive approach to building relationships and policies to back it up. Parents and practitioners working in a partnership have the most benefits for all parties involved.

Evidently, early years' service engaging with parents in a partnership is of vital importance and has potential benefits for 
all parties. This strategy needs to highlight how important having a partnership is and how important supporting the parents to create a quality home learning environment is.

\section{Literacy of Media}

Literacy has been described as the ability to read for knowledge and write coherently and think critically about the written word. Literacy can also include the ability to understand all forms of communication, be it body language, pictures, video \& sound (reading, speaking, listening and viewing). Evolving definitions of literacy often include all the symbol systems relevant to a particular community. Literacy encompasses a complex set of abilities to understand and use the dominant symbol systems of a culture for personal and community development. In a technological society, the concept of literacy is expanding to include the media and electronic text, in addition to alphabetic and number systems. These abilities vary in different social and cultural contexts according to need and demand. Within a highly idealist modern context, individuals must be given lifelong opportunities to move along a continuum that includes the reading, and writing, critical understanding and decision-making abilities they need in their community. In an historical context, literacy has always been a difficult problem for world's peoples, as measured through the centuries.

Media literacy is to some extent inevitably framed here as a matter of self-protection, of being able to filter out or deal with things that might be found inappropriate or unwelcome - and thus there is a moral discourse (or a discourse about media effects) that continues to inform the debate. Yet in practice, media literacy is being defined rather more broadly, as a kind of cultural competence - a matter of understanding how the media work, of being able to access and evaluate what you see, and to match it to your needs as a consumer.

It is important for teacher to have, as starting point, an agreement of what constitutes technology education (Brown, 1995 in Flavel L). The teaching technology as a school subject began early last century with the intent of providing working class children with 
knowledge, skills and values necessary to survive the effects of industrialization (Brown, 2000; Petrina, 2000 in Flavel).

Technology education is defined by Brown (1995), as a process by which society identities human problems and seeks solutions to solve them. Brown describestechnology education as having a number of inter linked phases, beginning with the identification of a problem or need. Next comes an investigation and the conceptualization of a solution to the problem. This followed by the design and construction of an object, system or environment to overcome the problem.

This solution is applied and followed finally by an evaluation of its success (which may lead to further refining and design). Brown's description is in accord with the design process outlined in "Technology with New Zealand Curriculum" (Ministry of Education, 1995) with the addition of a strand of learning considering technology in the social context.

However, a non-prescriptive and holistic curriculum where learning areas are integrated, many teachers have struggled to notice and therefore extend children's technological education. While teacher education institutions have included "Technology" as department for many years, and students teacher in training have learnt about skills. Knowledge and technological process, the focus has been on the curriculum of the compulsory sector rather than developing guidelines for appropriate technological practice for children in every childhood education.

At the same time that the development of technological education has been happening in New Zealand, there has been immense development in technology of an electronic digital nature (Bolstad, 2004). In ECE in New Zealand, these technologies are commonly known as information communication technologies (ICT). It is no wonder that there is confusion about terminology (Brown $\&$ Vossler, 2000). In the past ten years, since the publication of the Whaariki, ICT has featured more and more in ECE practice, and in literature, and authors often use the word technology when referring to ICT. To clarify these terms and specifically their meaning in ECE, the folly owing reviews of New Zealand literature seeks to 
establish a common meaning for ICT and technology in education.

It is my contention that schooled literacy, which traditionally sees the acquisitionof the ability to construct and interpret text as largely an individual activity,bounded by the concept of text as linear and fixed, is no longer adequate. That theterm 'computer literate' part of current teaching discourse is in itself indicativethat the notion of literacy has shifted in schools. There is an ongoing tension forschools between the professional understandings of the ways in which thecurriculum should be responsive to a changing society and the demands placedon schools by the statutory requirements of the National Curriculum andassociated assessment arrangements.

In schools, being a computer-literate student has largely meant acquiring atechnical expertise that enables a competent use of the available hardware.However, a much more complex and exciting understanding of computerliteracy is available and it is a lifelong literacy. This entails the ability toconstruct and manipulate text, which is not seen as linear but multidimensionaland multimedia and which is no longer fixed but infinitely changeable.

Themodel here is far closer to that required by school leavers at the beginning of thenew millennium's world of literacy where, for example, writing is rarelyundertaken as an individual task and text too is constantly subjected to changesand revisions not simply as a matter of style but in order to accommodate therapid shifts in information being made available. Similarly, such informationmay well be accessed using the Internet, when reading skills need to extendbeyond book print to screen print, with the inclusion of graphics and anunderstanding of page layout and hyperlinks. Literacy here means knowing thateffective information acquisition requires an understanding of how texts areconstructed; otherwise readers become trapped in a model of reading whichrequires them to read screens sequentially simply in order to gain one piece ofinformation buried somewhere in the text. The argument here is that a truly'computer-literate' student would be able to access this information with greaterspeed and accuracy by virtue of understanding the construction of text on screenand of the text search facilities available to them. 


\section{The Role of Early Years Services in Literacy and Numeracy}

The home learning environment involves all the learning experiences provided at home including but not extensive to: reading with the children, is going on visits, playing letter or numbers, singing, drawing and painting. In quality early year's services children can build the foundations for future literacy and numeracy learning. The seeds of emergent literacy and numeracy can be sewn from the ages of birth to six. Children will be able to engage with the primary school curriculum at a greater level. Therefore; for all children to have good communication and oral skills and be ready to engage with mathematical language.

It must be noted at this point, that teaching literacy and numeracy in early years services does not have the same connotations that one associates with the primary school learning. The teacher is not giving the children sums and expecting them to read. It is done naturally through young children's medium, through play. Before children can learn to read they need to learn about language. Language is the key to later literacy success (Dickinson \& Tabors, 2001).

Young children being engaged in songs, music, stories, being given time to speak and hearing patterns of sound are all key in children's language development and hence, their literacy. Introducing books to children pays an important role in introducing the convention of how fun books can be. In numeracy, children need to become familiar with numbers. In the early years setting, it is about labeling toy boxes with numbers, counting the children in the class, providing opportunities for children to sort and draw on patterns. It is through these experiences children begin to familiarize themselves with numeracy (Anning\& Edward, 2006). This early year's strategy must be the role the early year's services can play in supporting emergent literacy and numeracy. It must be outlined clearly that children at this age do not learn to read or add but are introduced into literacy and numeracy in an appropriate an relative way to them.

\section{Literacy Acquisition}

Most students expected to leave primaryschool as literate and 
for those who did not, secondary schools provided learningsupport until they were literate or until they left school to become adultilliterates. Literacy was a basic skill, a one-off hurdle to be cleared and thenpretty much forgotten. The new literacy, however, cannot be contained in thesame way. There clearly exists a need to reconsider literacy as an ongoingdevelopment - referred to earlier as lifelong literacy. The acquisition of the newliteracy cannot be ticked off at eleven. Instead, while acknowledging the needfor basic schooled literacy, there should be a further taxonomy of literacy skillsacknowledged: basic, extended and advanced literacy skills, reflecting changesmade in reading and writing demands through ICT. Extended literacy, forexample, would include the understanding of text beyond the linear and thediffering demands made on the reader encountering this type of text.

Advanced literacy would demonstrate the sophisticated understanding of theconstruction of text with a spatial dimension, the interaction of text withgraphics, which in turn may require interaction from the reader, who may thenbecome the writer. In one sense, it is a post-structuralist view of text.

In much the same way as literary theory was seen as a challenge to the verydefinition of literature and literary analysis, hypertext is seen as a challenge tocanonical and established text and thereby traditional literacy skills. But hypertextexists and cannot be un-invented; indeed, a new technical language is emerging inrelation to it. And as with literary theory, not too much time will pass beforehypertext itself becomes part of the established way of reading and writing. Literacy has expanded to include several types of literacies. 'Literacies'stresses the issue of access to the world and to knowledge throughdevelopment of multiple capacities within all of us to make sense of ourworlds through whatever means we have, not only texts and books.

\subsection{The Rationale of Literacy}

Given the powerful role of literacy in society, it is inevitable that standardsof literacy and definitions of what constitutes `being literate’ should be aconcern for educators. With the 
development of more and more uses andfunctions for literacy, it is certainly the case that children need to achieveever higher standards of literacy to 'be literate' in their society. One majorfactor in raising standards must be the quality of the teaching of literacythat children experience, particularly during the primary phase of schooling.

High-quality literacy teaching demands high-quality literacy teachers, andany education system must attempt to maximise the expertise of teachers inteaching literacy. In order to direct improvements in the selection, trainingand professional development of teachers of literacy most profitably, agreat deal can be learned from a study of those primary school teachersidentified as effective in the teaching of literacy.

Such a study was the aim of the research described in this book. Thisresearch project was commissioned by the Teacher Training Agency withthe aim of understanding more clearly how effective teachers help childrento become literate. The research study involved a close examination of thework of a sample of teachers whose pupils were making effective learninggains in literacy. We also compared the work of these effective teacherswith that of a more random sample of teachers whose pupils were makingless progress in literacy. The book gives an account of the project, its mainfindings and their implications for policy and practice, as well as relatingthe outcomes to insights gained from other research and commentary.

\subsection{Defining Literacy}

In order to begin a study of effective teachers of literacy, we ${ }^{\circledR}$ rst needed tobe clear about that we actually meant by literacy. This, of course, canand has been de®ned very widely. For our purposes, literacy was seen asa unitary process with two complementary aspects, reading and writing.

The characteristics of literate students should be followed some points; they are as follows:

20. read and write with confidence, fluency and understanding; 21. be interested in books, read with enjoyment and evaluate 
and justifytheir

22. preferences;

23. know and understand a range of genres in fiction and poetry,

24. be familiar with some of the ways that narrativesare structured through basic literary ideas of setting, character andplot;

25. understand and be able to use a range of non-action texts;

26. be able orchestrate a full range of reading cues (phonic, graphic, syntactic, contextual) to monitor and self-correct their own reading;

27. plan, draft, revise and edit and their own writing;

28. have interest in words and word meanings, and a growing vocabulary;

29. understand the sound and spelling system and use this to read and spell accurately;

30. have fluent and legible handwriting

There were, in this analysis, three strands to the experiences that children needed in order to develop these competencies:

31. 1. word-level work: i.e. phonics, spelling and vocabulary;

32. 2. sentence-level work: i.e. grammar and punctuation;

33. 3. text-level work: i.e. comprehension and composition. 34.

\subsection{The Relation of Media and Education}

Media text often combine several 'languages' or forms of communication - visual images (still or moving), audio (sound, music or speech) and written languages. Media education therefore aims to develop a broad-based competence, not just in relation to print, but also in these other symbolic systems of images and sounds. This competence is frequently described as a form of literacy: and it is just as important for young people as the more traditional literacy of print.

Media education, therefore, is concerned Education is seen here as one (although by no means the only) way of spromoting media literacy; and to this extent, media educa- 
tion is now achieving a degree of recognition and support from government that is quite unprecedented of media education, there has been an uphill struggle over the past several decades to convince the government of the need for children to study the modern media; and so for those of us who have worked in this field for many years, this is (to say the least) an extraordinary development.

\subsection{Childhood and Media}

Children as young learners must be protected from the media abused. There are many factors why protecting children as one of the focuses in doing teaching and learning process. Children when they stay at their houses; so the parents must facilitate them with parental guidance while they watching audio-visual (television, video recorder). It is the same when they study at their schools; so that teachers must be responsible too. Children having different their own styles in consuming media as experienced. We should consider to all these dynamics point of view.

It is possible to identify two contrasting views of the relationship between children and media, both of which have been influential in popular and academic debate. On the one hand, there is the idea that childhood as we know it is dying or disappearing, and that the media are now a force of deliberation that is more open, more democratic, and socially aware than their parents' generation. In some ways, these two views are diametrically opposed, not least in their underlying assumptions about childhood; yet there are also some striking similarities between them.

\section{METHODS}

According to Hadi, research is the effort to discover, develop and test a knowledge using scientific methods. With efforts to obtain and collect data from research activities, use the following steps:

In research this approach executed is through qualitative approach. It means data is collected not form of numbers, but data 
were from manuscript interview notes field, documents personal, notes memo and other formal document. So the purpose of this qualitative study was to describe the empirical reality behind the phenomenon in depth, detailed and thoroughly. Therefore, the use of qualitative approach in this research is to match between the empirical reality with the theory that applies to the use their descriptive method. According to Keirl and Moleong Miller in the definition of qualitative research is a particular tradition in social science is fundamentally dependent on observation in humans on its own, and connect with the people in their local language and its terms.

Qualitative research methods are methods used to examine the condition of natural objects, where researchers are as a key instrument, data collection techniques are combined, the data analysis is inductive qualitative research results, and more emphasis on generalization of meaning. The consideration of qualitative research authors use this as expressed by Lexy Moleong:

35. Qualitative method is easier to customize what confronted with the reality.

36. This indirect method is the nature of the relationship between researchers and respondents.

37. This method more sensitive and conform to the influence of a joint against the value of management patterns that must be faced.

Descriptive research studying the problems in society, as well as the procedures applicable in the community as well as particular situations, including about relationships, activities, attitudes, outlooks, as well as the processes that are being conducted and the influences of a phenomenon.

Based on the characteristics of this research and the attention focused to study, then the theoretical mentioned by Meltzer, Petras, and Reynold is phenomenology (Bogdan and Biklen, 1992: 31) that all qualitative researchers in certain ways reflect the phenomenological perspective. It means that all researchers will try to understand hard about certain condition and what kind of interaction which suitable for people to become as well as possible. Particularly in 
research to understand what is the meaning of events and interactions for people can be in certain situations. To research in the understanding of the object; it will make interpretation of the scheme first conceptual.

\section{Method of Investigation}

Here the writer is going to use the descriptive qualitative research to conduct this study. Since this study needs some analytical requirements, so that the deep analysis about resources which come from the many sources of the objects; fully needed to expand the explanation later on.

However, the writer is going to use field research in this study. He will find many sources which relate with the problems stated in previous chapter. It is needed because again, the condition needed to create deep analyses which make some assumption more deep and narrow. Moreover, this research involves identifying and locating sources that factual information or personal/ expert opinion on a research question; necessary component of every other research method at some points.

\section{Procedure of Collecting Data.}

In this research an approach that is done is through a qualitative approach. It means data is not collected by numbers, but the data derived from the manuscript interview a record of the ground, personal documents, field notes and other formal document. So the purpose of this qualitative study was to describe the empirical reality behind the phenomenon in depth, detailed and thoroughly. Therefore the use of qualitative approach in this research is to match between the empirical reality with the theory that applies to the use their descriptive method.

In conducting his research the writer will do some following procedures as follows:

a. Direct observation:

As a method of scientific observation conducted by observation and recording in a systematic method to phenomena or occurrence is investigated. The implementation of observation 
in the study is done in places that deals with learning school a school like each of the classrooms where occurring interaction, formal learning the office of chief school, the teachers and all other space. Besides that there are some place outside school (places where students performs activities extra curriculum or activity order a process the activities of learning as boy scout, and sports).

Observation especially devoted to obtain data pertaining to that which is wrough (cultural behavior) and what which used (cultural artifacts) by the participants. In doing observation, researcher is able to put himself in participant or non participant. In addition, researchers can also walk in a way frankly (overt) or furtively.

The level of involvement in the observation researchers varies. When researchers only observing and not involved with the guilty person or activity then said non participant. Otherwise, when researchers do what other people do for obtaining a lesson of a certain behavior, hence called participants active or full of one. Observation involved as a main strategy to keep quality data qualitative in research, that is possible for researchers used various data sources. Research also engaged in some times when process of activities the learning process of students who are being observed in certain period of time observe various events that occur, review talks people, asking questions directly into a source of information. This strategy maximizes the prospect of researchers to produce questions about symptoms lessons he learned were valid. The involvement of researchers in daily life of the citizens who conducted research makes him became part of a reasonable in their lives; so that they will behave as conventionally as before the presence of researchers there. This reduces problem reactivity, namely the trouble because there is a tendency people behave other when they realize seang observed by the foreign. The involvement of researchers allow formulated the questions that makes sense for the citizens of subjects in the local language or phrases.

Observation involved give an intuitive understand- 
ing to researchers about the meaning of things that are found in its societies. A lot of problems research that can only be described in an adequate manner through the observation involved. Besides, in doing observation, researchers always led to a focus. Therefore, all the observation should be made a note of the field as soon as possible after observation. The note is listed in a format that has been prepared by researchers according to a code that they made.

b. Deep interview

Interviewing is a frequent part of social lifesurounding most of us: it can be heard from the televison, radio, watching people being interviewed. Miller and Crabtree (1999) states that the interview genre with its turn-taking conventions and expectations for participants roles, etiquettes, and even linguistic phrases is usually shared cultural nowledge. It is exactly because interviewing is a known communication routine that the method works so well as a versatile research instrument - in fact, although there is a range of a qualitative research techniques available for researchers, the interview is the most often used method in qualititative inquiries. It is regularly applied in a variety of applied linguistic contexts for diverse purposes.

There are different types of interviews: the highly structured version shares many similarities with quantitatives written questionnaires and therefore it will be discussed here only very briefly.

Interview with informants done in two ways. The first is by listening to and call attention to something which said by informants. After interviewing is done, the researcher would make a transcript immediately into a transcript the results of an interview. Certainly using tape recorder, based on the willingness of an informer after recording finished researcher transcript in the interview lists.

Just like an interview, then after doing observation the task of researcher is to make a transcript as the results of observation. 
3. Documentation

Documentation used to collect the data from the source non-insani of documents from a recording. Lincoln and guba (1985) define recording as any writing or statement prepared by or for individul or organization by purpose prove the existence of an event or meet accounting. While documents which are not prepared specifically for some purpose, as letters, a diary, record cases, scripts and photos.

There are several reasons the use of the document as a source of data. First, source is always available and cheap (especially in terms of its acquisition). Second, records and documents are sources of information which stabled, precision in reflecting situation that happen in the past and can be analyzed back without undergoing changes. Third, records and documents is information source rich, things contextually relevant and fundamental in context.

\section{Research Activities}

This research conducted in three major stages. Each stagess consisting of particular activity. Activity that is performed at every stage, according to Nasution (1996: 33) is the stage orientation, exploration, member check.

a. The Step of Orientation

At this stage done prasurvey to the research to get the picture about the problem of subjects. It determined subjects at the beginning, under deep investigation through crowd reading good theoretical concept nor study prefatory relevant overcoming the research, and choose a spot research.

b. Exploration Stages

At this stage the studies the field against data sources about the implementation of multiple intelligences in sdit assalamah ungaran to gather all the data and information necessary.

c. Member check stages

At this stage of making a written report was shown responded to assess conformity with the interview judgment documents and observation, then requested explanations to related 
elements if is deemed necessary if the data and information collected incomplete. This is meant for all the data can be secured truth without doubt will validitasnya.

\section{Technique for Analyzing Data}

After collecting data, the writer then analyzed the data. In reporting the result, the writer will use the descriptive analysis method. Since the descriptive method is used in the literal sense of describing situation or events. Isaac (1990: 52) states that it is the accumulation of data based that is solely descriptive; it does not necessarily seek or explain relationship, test, and hypothesis, also make prediction, or getting at meaning and implication. In this study, the writer used descriptive analysis to report the result of the analysis from the data was taken.

Isaac (1990) also states that descriptive method is applicable in this study since its purpose is to describe systematically the condition of existing phenomena. Fourth, this source is often a legal statement that can fulfill accountability. Fifth, a source of respondents, this is not like human being namely non-reactive.

Technique analysis of data used in this research is a qualitative analysis. According to Moleong (2000: 198) analysis of data qualitative data, is process of drawing up catagorizing the theme or categories, so as to be interpreted or interpreted. In order to be able to interpret and interpret the data needed perseverance, properly carefulness, patience, and creativity that high that researchers able to provide meaning in any phenomenon or of existing data.

Analysis of data used in this research is on the model of interactive analysis (Miles \& Huberman, 1984: 20). This technique used because for the purpose of researching the process and meaning.

In this model there are three components of the analysis. They are as follows: 1) The stage of reduction of the data. 2) Stage or cereal offering displays data. 3) The stage of verification of data / the withdrawal of conclusions made in the form of interactive with the process of collecting data as a cycle. 


\section{The Data Reduction Technique}

Reduction data, namely the process of selection rough and still raw data is constantly during ongoing research, lasts through stages make a summary, decoding, initializing theme and preparing a summary. Stage reduction data done to review overall data collected by of a field so as to be found things staple of a field so as to be found things basic of an object researched the. The stage of data reduction to be done to analyse overall the data collected from the field so as to be found at the heart of the field so that things can be found.

Based on the description above, so there are some components that should be concerned as follows:

a. Collecting data and information from the data recording; the result of interviews and observation result.

b. Finding a core or main subjects which are considered important of every aspect in research findings.

\section{Stages of Displaying Data}

Displaying data / presentation of data is a process of gathering information based on data owned and arranged in good and sequenced so that it may easily seen, read and understood about an event and act in the form of text narrative. At this stage done conclusion towards research findings in the implementation of multiple intelligences at SDIT Assalamah Ungaran.

There are many varieties of documents, so there is no guideline book in documentation itself. Nevertheless, documentation should contain elements of objects record; a means / step registration; aspect and types which recorded manner of writing and notes. This kind of method which is used in collecting the data relating to SDIT Assalamah Ungaran.

There are some activities for examining in this stage, they are as follows:

a. Establishing a descriptive summary and doing systematically, so that the major theme can be easily undestood.

b. Giving meaning to the summary with the appropriateness towards the research. 


\section{Verifying Data of The Research}

Verification of lab data /drawing conclusions, namely based on data obtained from various sources then researcher take drawing conclusions which still be temporary while looking for data advocates or rejecting a drawing conclusions abou it.

At this stage doing certain test about a conclusion that has been taken with the data comparison some theories. Testing is intended to see the truth of the results of an analysis so creating a conclusion might be believed.

There are some steps in doing this kind of test. They are as follows:

a. Testing conclusion that has been taken by comparing theories propounded pundits, especially the undirected and relevant one.

b. Performing the process of member check or performing the process of checking reëxamined, ranging from the implementation of prasurvey, doing interview from the main source, observing of the data, and giving information.

c. Making a general conclusion to be reported as a result of research that has already been done.

However, the writer also analyzed the data taken by way of certain points: field analysis, checking data, checking the technique of collecting data, and also checking against supplies who used and personnel who gave assist for the data. After collecting data, infering data is intended to discover patterns and a proposition. Concluding, intended to find a moderate degree of categories, an order of the process of categories.It thereby, used to build a theme / the concept of the findings.

Based on research purposes which have to be achieved, and technique analysis of data in this research is a qualitative analysis descriptive namely described how the implementation of multiple intelligences in SDIT Assalamah Ungaran.

In this research analysis for the data collection done by making a transcript as thresults of interview which is taken from observation and documentation. Then making a summary list interviews and observation that is a list of containing a summary of raw data the result of collecting data from the field. 
Just like an interview, then after completing the stage of observation he researcher made a transcript as the results of observation. While doing the observation; the researcher read and tried to understand them and made a summary based on list results interview and observation.

\section{FINDINGS}

\section{Childhood and Media}

Our approach to media education is bound to depend upon the assumptions we make about the relationships between media and their audiences. To what extent do the media simply impose 'negative' messages on passive minds, as many media educators have tended to suppose? To what extent do audiences have the power to create their own meanings and pleasures? What ways characteristics and needs? Public debates about the issues typically overstate the negative and the positive influences of media in children's live.

It is possible to identify two contrasting views of the relationship between children and media, both of which have been influential in popular and academic debate. On the other hand, there is the idea that childhood as we know it dying or disappearing, and that the media are primarily to blame for this. On the other hand, there is the idea that the media are now a force of liberation for children -that are creating a new 'electronic generation' that is more open, more democratic, and more socially aware than their parents' generation. In some extends, these two views are diametrically opposed, not least in their underlying assumptions about childhood; yet there are also some striking similarities between them.

The notion that the media are destroying childhood is most popularly associated with the American critic Neil Postman's book The Disappearance of Childhood (1983). Essentially, Postman argues that our modern conception of childhood was a creation of the print media; and that new media, particularly television, are destroying it. According to him, this is primarily to do with children's access to information. Whereas acquiring print literacy took a long period of apprenticeship, we don't have to learn to read or interpret television. Television is, he argues, a 'total disclosure medium': 
through television, children are increasingly learning about 'secrets' of adult life such as: sex, drugs, violence - that would previously have been hidden in the specialized code of print. As a result, they are increasingly coming to behave like adults, and to demand access to adult privileges.

One can certainly challenge Postman on the ground on his evidence, both about his explanation of the causes. But his argument also rests on a set of assumptions about childhood and about the media that are highly questionable. Ultimately, Postman's position is that of technological determinist: technology is seen to produce social (and indeed psychological) change, irrespective of how it is used, or the representations it makes available. While he distances himself from the so-called Moral Majority, Postman clearly wants to return to imaginary Golden Age of traditional moral values and thereby to reinforce adult authority and control. Significantly, he is also directly opposed to the use of television in education: for him, the school is the last bastion in the defense of print culture.

More recently, we have seen the emergence of an argument that is in some respects a mirror image of Postman's. Perhaps the most distinctive expression of this is by the American journalist and media consultant Don Tapscott (1998), in his book Growing Up Digital. In some extends Tapscott seems to support Postman's diagnosis, although he interprets it in a very different way. He agrees that the boundaries between childhood and adulthood are blurring; and he agrees that media technology particularly digital technology is primarily responsible for this. But rather than regretting this development, he sees it as a form of liberation or 'empowerment' for young people.

The argument here is partly based on the contrast between 'new' and 'old' technologies. Tapscott in fact sets up a direct opposition between television and the internet. Television is seen as passive, while the internet is active; television broadcasts a singular view isolates, while the internet is democratic and interactive; television isolates, while the internet builds communities; and so on. Just as television is the antithesis of the net, so the 'television generation' is the antithesis of the 'net generation'. Like the technology they 
now control, the values of the television generation are increasingly conservative, 'hierarchical, flexible and centralized'. By contrast, the members of the 'net generation' are 'hungry for expression', discovery and their own self-development': they are savvy, self-reliant, analytical, creative, inquisitive, accepting of diversity, socially conscious, globally oriented all, it would seem, because of their intuitive relationship with technology.

Here, again it is possible to challenge Tapscott on the grounds of his evidence or lack of it (Buckingham, 2000) although it is his underlying assumptions that there are particularly dubious. As with the 'death of childhood' thesis, this argument reflects a form of 'media determinism', albeit of a very different kind. According to Postman (1998:2000a) children as vulnerable and in need to protection from the corrupting influence of media technology; while Tapscott sees them as naturally wise, and as having an innate thirst for knowledge which media technology can satisfy. Where Postman wants to return to a situation in which children knew their place, Tapscott argues that adults should try to 'catch up' with their children. Where Postman places his faith in adult authority, he looks the technology alone as the solution to social problems. In some respects, therefore, these apparently contrasting arguments could be seen as two sides of the same coin. Both have an undeniable appeal: they tell simple stories that speak directly to our hopes and fears about children's futures. Yet ultimately, they are based on highly questionable and indeed unduly generalized views of childhood and of media technology and of the relationship between them.

\section{Changing Childhoods}

In some respects, both these arguments could be seen as a symptomatic of a sense of crisis that has been brought by wider social changes. While the primary focus in this chapter is one of the roles of the media, it is important to locate briefly within the broader account of the changing social position of children. Generalizations about such changes are obviously risky. We cannot talk about children as a homogenous category: what childhood means, and how it is experienced, it depends upon other social factors, such 
as gender, 'race' or ethnicity, social class, geographical location, and etc. Nevertheless, it is possible to identify a number of general ways in which children's lives changed over the past century, and specifically in the past three or four decades.

Thus, we have seen a gradual shift away from extended families, and then increasingly to non-traditional family structures of various kinds most notably single-parent families. Buckingham (2008: 21) says children are now much more likely to be confined to their homes, and much less independently mobile, then they were twenty years ago; and while parents now spend much less time with their children, they are attempting to compensate for this by devoting increasing economic sources to child-rearing. Meanwhile, there has been a steady extension of the years of compulsory schooling, and of the proposition of young people continuing in post-compulsory education. Increasing numbers of children are also now in preschool education of some kind. On the other hand, youth unemployment is rising, and in some countries state benefits for young people has been withdrawn; and as a result, young people are now becoming increasingly dependent upon their parents. There have also been significantly dependent significant changes in peer group culture. Young people are now having sex earlier than in previous decades; and they are maturing physically at an ever-earlier age. Drugs have become an almost taken-for-granted aspect of young people's recreational experience; and despite the 'war of drugs', drug use is now at higher level than ever before. There is also increasing anxiety about the incident of child crime, although statistically children are much more likely to be victims of crime than other age groups.

As a result of these developments, there have been changes in children's status as a distinctive social group. On the other hand, there is growing concern about the need to protect children, particularly from forms of abuse; on the other, there have been increasingly punitive attempts to deal with a perceived breakdown in discipline. At the same time, the issue of children's right has become much more significant in recent years. Following the UN Convention on the Rights of the Child, many countries have passed new legislation to protect children's right, both in family and in their dealing with state 
agencies. However, this concern for children's rights goes along with new emphasis on children as a potential market. If capitalism can be said to have created 'the teenager' in the 1950s, children are now increasingly addressed directly as a consumer market in their own right, rather than simply as a means of reaching parents. Nevertheless, over the past two decades, many Western countries have seen an increasing polarization between rich and poor, and the creation of a growing underclass, in which children are disproportionately represented.

These changes clearly do not tell a simple story; and they will obviously affect children in different ways. Indeed, in some respects they point to a growing polarization among children not only between rich and poor, but also between those who are living 'modern' and 'traditional' childhoods. In general, however, it is clear that relations of authority and power between adults and children are changing. While there are some who wish to reassert traditional relationships, and to turn to an era in which children were 'seen but not heard', there are others who welcome these changes as an extension of democracy and of the rights of citizenship to children. At the same time, we might well argue that children have gained power; not merely as citizens but also as consumers; and indeed that the two may have become impossible to separate.

These changes both reinforce, and are reinforced by changes in children's relationships with the media. Children are being empowered and yet simultaneously denied the opportunity to exercise control.

\section{The Implication of Media Literacy in Global Era}

\subsection{Technologies}

As we have seen, discussions of young people's relationships with the media often attribute a determining power to technology. Such arguments are problematic for several reasons. Technologies do not produce social change irrespective of how they are used; nor are the inherent differences between technologies as absolute as is often supposed. In this case, we need to consider how technological changes are related both to econom- 
ic developments and to changes in the behavior of audiences.

Recent developments in media technologies can be understood, they are as follows: firstly, as a matter of proliferation. Since the advent of television, the domestic TV screen has become the delivery point for an ever broader range of media. The number of channels has grown, both on terrestrial television and (more spectacularly) with the advent of cable, satellite and digital TV; while the screen is also being used for video in various forms, as well as for the ever-broadening range of digital media, from computer games and CD-ROMs to the internet.

Secondly, there has been a convergence between information and communications technologies. Over the coming decade, the advent of digital television, internet set-top boxes, online shopping, video on demand and other developments will increasingly blur the distinctions between linear broadcast media such as television and 'narrowcast' interactive media such as internet. Like the other, developments identified here, this has been commercially driven; but it has also been made possible by digitization.

These developments have implications, thirdly, in term of access. Hintherto expensive aspects of media production, and a whole range of media forms and options, have been brought within reach of the domestic consumer. The price of video camcorders, digital cameras and multimedia PCs has steadily fallen as their capabilities have increased; and at least in principle, the internet represents a means of communication that cannot be exclusively controlled by small elite. In the process, it is argued, the boundaries between production and consumption, and between mass communication and interpersonal communication, are beginning to breakdown.

These changes have several specific implications for children. Children and parents are among the most significant markets for these new technologies. Cable and satellite television, for example have been strongly targeted towards the younger audience, while much of the advertising and promotion for home computers trades in a popular mystique about children's 
natural affinity with technology (Nixon, 1989). Technology is also being used in more individualized ways.

Similarly, many of the new cultural forms made possible by these technologies are primarily identified with the young. Computer games, for example, are predominantly addressed to the children's and youth market, while popular music is increasingly generated by digital technology, via sampling, editing and other software. The increasing accessibility of this technology is also enabling some young people to play a more active role as cultural producers. More and more teenagers have computers in their bedrooms that can be used to create music, to manipulate images or to edit video to a relatively professional standard. Nevertheless, we should no exaggerate the scale of these developments. Level of access to technology will increasesignificantly in the coming years, as prices fall; yet there is also a polarization between the 'technology rich' and the 'technology poor', both within societies and in global terms (Wartella et al., 1990).

Children growing access to media is generating increasing concern about their exposure to material hitherto largely confined to adult-most obviously to 'sex and violence' (both of which are often very loosely defined). When compared with older technologies such as the cinema or broadcast television significantly undermine the potential for centralized control by national governments. Video for instance; has made it possible to copy and circulate material to a much greater extent than has ever been the case with moving images. It also makes it possible to view it, non in a public space to which access can be controlled, but in private space of the home; and to do so at a time chosen by the viewer, not by a centralized scheduler working with ideas about what is appropriate for children to watch. A large majority of children have seen material on video which they should not legally have been able to obtain (Buckingham, 1996a).

This anxiety about control is accentuated by the advent of digital technology. It is now possible, not only for material to be easily copied and circulated, but also for it to be sent across 
national boundaries on the telephone line. At present, the internet is relatively decentralized medium: anyone with access to the technology can 'publish' anything the like and anyone with else can get access to it. Via the internet, children can communicate much more easily with each other and with adults, without even having to identify themselves as children. And of course, the privacy and anonymity afforded by the internet particularly lends itself to the easy dissemination and sale of pornography. This situation has led to growing calls for stricter regulation and censorships; and to the search for a 'technological fix' in the form of the V-chip or so called 'blocking software' that will prevent children from gaining access to material that is deemed undesirable. Yet evidence of the effectiveness of such devices is decidedly limited (WaltermannabdMachill, 2000).

\subsection{Economics}

These technology developments have helped to reinforce and be reinforced by fundamental institutional and economic changes in the media industries. The past two decades have been characterized by growing privatization. The media have been inextricably caught up in the broader commercialization of contemporary culture, in which field such as politics, sport, and health care; indeed education itself have increasingly been 'invaded' by commercial forces. Meanwhile, public sector provision for example in broadcasting has gradually been commercialized from within; and regulation concerned with the social and cultural functions of the media is being abandoned in favor of narrower concern with morality.

One inevitable consequence of this development has been the integration and globalization of the media industries. The media market is now dominated by a small number of multinational conglomerates; and global brands now provide an international languages or 'common culture', particularly among young people. For nationally based companies, success in the international market is increasingly necessary for survival. Significantly, most of these global corporations are cross-media empires: they inte- 
grate broadcasting, publishing, media and digital technology, and many cases have interests in both hardware and software. Yet integration does not necessarily mean homogenization: growing competition has also resulted in the fragmentation of audiences, and the rise of 'niche marketing'. Media are increasingly targeted towards specialized fractions of the mass audience, albeit on a global scale; and new technologies also permit more decentralized communications, and the creation of 'communities' that transcend national boundaries.

These developments affect children in quite ambiguous ways. Children have effectively been 'discovered' as a new target market only in the past view decades. In the case of commercial television, for example, children were not initially seen as an especially valuable audience. In the early decades of the US commercial system, programs would be provided for children only at a minimum cost, and at times when other audiences were not available to view (Melody, 1973). In the contemporary era of niche marketing, children have suddenly become much more valuable: they are seen to have significant influence on parents' purchasing decisions, as well as substantial disposable income of their own. At least within the media industries, the vulnerable child in need of protection has increasingly given way to the child as 'sovereign consumer'. The formation and development of 'youth culture' and more recently, of a global 'children's culture' are now inextricable from the commercial operations of the modern media. As a result, today's children may have more in common with children in other cultures than their own parents (Ohmae, 1995).

However, we should be wary of economic of determinism here. It is far too easy to fall back on traditional notions of children as vulnerable to commercial exploitation or to the seductions of media imperialism. A large portion of commercial products aimed at children simply fail to fail to generate a profit: the market is highly competitive an uncertain. To this extent, there is some justification in producer's recurrent claim that children are volatile, complex market, which cannot easily 
be known and controlled.

Nevertheless, the fact remains that children's leisure activities are becoming steadily more privatized activity of some kind, while the cultural goods and services they consume increasingly have to be paid for in hard cash. The public spaces of childhood both the physical spaces of play and the virtual spaces of broadcasting have increasingly fallen into decline or been overcome by the commercial market. One inevitable consequence of this is that children's social and media worlds are becoming increasingly unequal. The polarization between rich and poor is positively reinforced by the commercialization of the media, and the decline in public sector provision. In the, case of computers just as in the early days of television, those with greater disposable income are the 'early adopters': they have newer and more powerful equipment, and more opportunities to develop the skills that are needed to use it. Poor children simply have less access to cultural goods and services: they live, not just in different social worlds, but in different media worlds as well.

\subsection{Text}

Perhaps the most obvious manifestation of these technological and economic developments is in the changing characteristics of media texts that is the television programs, movies, games, and other artifacts children are engaging with. On one level, this can be seen as a further consequence of technological and economic convergence. More and more media texts are somehow 'spin-offs' or advertisements for other texts or commodities; and the media have become much more closely bound up with the merchandising of a whole range of other products.

As a result, intertextuality has become a dominant characteristic of contemporary media: texts are constantly referring to and drawing upon other texts, often in ironic ways. Many contemporary cartoons, for instance, self-consciously draw upon other media in the form of pastiche, homage, or parody; they juxtapose incongruous elements from different historical periods, genres or cultural contexts; and they play with established 
conventions of form and or viewer as knowing 'media literate' consumers.

Finally, many of these new media forms are characterized by types of interactivity. As we have seen, some of the more utopian advocates of interactive multimedia (such as Tapscott) have seen it as a means of liberation from constraints of more traditional 'linear' media such as film and television. Hypertexts, CD-ROMs and computer games have been seen to abolish the distinction between 'reader' and 'writer'. In consequence, at least some of these new media appear to exercise a much stronger fascination for their users than the 'older' media with which they are now competing.

Many of these developments are dictated by primarily economic logic. As media have become increasingly commoditized, producers need to exploit success across a wider range of media within a shorter time scale, are bound to use the same material in different forms. Meanwhile irony has become a useful marketing device, enabling media corporations to secure additional profit by recycling existing properties; and 'interactivity' is often little more than a form of packaging.

Nevertheless, many these characteristics apply with particular force to media texts that are aimed at children and young people (Buckingham, 2000). As children's access to technology increases, they no longer have to watch or read what their parents choose. As the 'niche market' of children grows importance, they are increasingly able to confine themselves to media that are produced specifically for them. Indeed, the new 'postmodern' cultural forms that characterize children's and youth culture often exclude adults: they depend upon particular cultural competencies and on a prior knowledge of specific media texts (in other words, on a form of 'media literacy) that are accessible only to the young.

Yet TV programs are not just TV programs; they are also films, records, comics, computer games and toys not to mention T-shirts, posters, lunchboxes, drinks, sticker albums, food, and crosses the boundaries between texts and between traditional 
media forms most obviously in the case of phenomena. In this process, the identity of 'original' text is far from clear: these commodities are packaged and marketed as merchandising following on. And this development is not confined to the work of exclusively 'commercial' corporations such as illustrated by the success of public service productions such as Sesame Street and Teletubbies.

It is also important to recognize changes at the level of content which, as in the case of Postman (1983), are often those that cause most alarm among adult critics. Postman (1983) argues that in the UK, children's television has steadily changes over the past twenty years to incorporate topics such as sex, drugs, and family breakdown that would previously have been considered taboo. Likewise, magazines and books aimed at the early teenage market have attracted widespread criticism for their frank and explicit treatment of such issues (Davies, 2002; Rosen, 1997).

Indeed, it could be argued that the age at which childhood ends at least as far as the media industries are concerned seems to be steadily reducing. Children's television producers, for example, now acknowledge that the bulk of older children's viewing is given over to 'adult' programs; and the content and style aimed at them clearly reflects this. The social issues addressed in children's dramas have much in common with those in adult's soaps; while the visual style pace of kids' magazine shows have clearly influenced the approach of 'adult' programs. While some critics have always complained about the precocity of children's programs, others are beginning to bemoan what they see as the infantilization of 'adult' television. Yet either way, it would seem that 'childishness' like 'youth' before it has become a valuable commodity for sale in the media market (Davies, Buckingham and Kelley, 2000).

\subsection{Audiences}

As the media have evolved, they have come to assume quite different kinds of competence and knowledge and to encourage 
very different forms of 'activity' on the part audiences. Contemporary media are increasingly addressing children as highly 'media literate' consumers. Whether they actually are more media literate, and what we might mean by that, is a rather more complex question, however, as we shall see in the following chapter. Thus, some claims that there is now much greater choice for choice for consumers, while other argues that such choice is merely spurious. For example, the proliferation of television channels is available for children, even taking accounts of the fact that much of it is frequently repeated. Whether this increase will be sustained over the longer term is more debatable, however: the amount of new product cannot keep pace with the increase in outlets for it - not least because the audience for each channel is decreasing as more become available, and hence the funding for new production will decline. In practice, therefore, what viewers are more likely to be offered is ever-increasing opportunities to watch the same thing (Buckingham et al, 1999).

These issues are to some extent compounded by interactivity. Leaving aside the question of whether surfing the web actually is more active than surfing TV channels or browsing through a magazine, there are significant questions about whether audiences actually want greater 'activity'. Even for regular users. There is room for skepticism about the 'empowerment' that is apparently offered here. The web clearly allows users much greater control over the selection of content and the pace at which it is read. Yet in the process it also permits much more detailed surveillance of consumer's behavior: it is now very easy to track users' movement between and within particular web site, and thereby to build up consumer profiles which can subsequently become the basis for electronic advertising. Children have become key targets in this respect (Center for Media Education, 1997).

Finally, there are questions about the growing fragmentation of audiences, as the texts are increasingly targeted at specialized groups of consumers. Multi-channel television, for example, may bring about the decline of broadcasting (and 
'common culture' it makes possible) in favor or 'narrowcasting', while the internet is well advanced for those with specialist or minority interest. Yet in longer term, it remains to be seen how far consumers actually want to pursue wholly individualized or 'customized' uses of media, or whether they want a more shared experience at least to extent of being able to talk what they have seen in the following day. Here too, the ideas that new necessarily offer a form of 'empowerment' is open to question.

Nevertheless, these changes have specific implications for our views of the child audience. At least in English-speaking world, sensational stories about the harm the media allegedly inflict on children have increasingly come to dominate the headlines. There is a clear acknowledgement that children are no longer restricted to material that is designed for them although research suggests that in fact they have always preferred 'adult' media, at least insofar as they could gain access to them (Abrams, 1956). Yet if public debates about children and the media have become more and more preoccupied with defending children from harm, the views of those who work within the media industries seem to be moving in a rather different direction (Del Vecchio, 1997). Here children are no longer predominantly seen as innocent and vulnerable to influence. On the contrary, they are increasingly regarded as sophisticated demanding, 'mediawise' consumers. The shift is certainly apparent in the recent history of children's television (Buckimham et al, 1999). The broadly 'child-centered' ethos that flourished in Britain during 1960s and 1970s is increasingly losing ground to an essentially consumerist approach. The child viewer is no longer seen as the developing consciousness of psychological imagination, but as sophisticated, discriminating, critical consumer. Children have become 'kids'; and kids, we are told, are 'smart', 'savvy' and 'streetwise'. Kids are hard to please; they see through attempts at deception and manipulation; and they refuse to be patronized.

This discourse is in turn often connected with arguments about children's right. Internationally, the most successful exponent of this approach has been dedicated children's channel 
Nickelodeon (owned by the US media giant Viacom). What we found here is rhetoric of empowerment - a notion of the channel as a 'kind-only' zone, giving voice to kids, taking the kids' point of view, as the friend of kids (Laybourne, 1993). This is reinforced in this channel's publicity and on-screen continuity materials. Significantly, children seem to be defined here primarily in terms of being not adults. Adults are boring; kids are fun. Adults are conservative; kids are fresh and innovative. Adults will never understand; kids intuitively know. Yet despite its emphasis on 'children's right', the discourse does not define children as independent social or political actors, let alone offer them democratic control or accountability: it is a discourse of consumer sovereignty masquerading as a discourse of cultural rights.

\subsection{Implication for Education}

In several respects, recent developments in the media could be seen to reinforce - and to be reinforced by changes in childhood, of the kind identified earlier in this chapter. Both are characterized by a growing sense of instability and insecurity: established distinctions and hierarchies are breaking down, as new cultural forms and new identities emerge. In relation to the media, as in many other areas of social life, previously distinct boundaries between children and adults are disappearing. Yet Buckingham (2000) says such boundaries are simultaneously being reinforced or redrawn. The separation between children's and adult's media worlds is becoming more apparent, although the terms of that separation are changing. Older children can no longer be so easily 'protected' from experiences that are seen to be morally damaging or unsuitable. The walls that surround the garden of childhood have become much easier to climb. And yet children particularly younger children are increasingly participating in cultural and social worlds that are inaccessible, even incomprehensible, to their parents.

So what are the implications of this situation for education? Obviously, it would seem to reinforce the urgent need for 
systematic programs of teaching and learning about the media. What we need to know about this chapter is; the central points to the central role of the media in children's lives, and their significance in defining the illustration the increasing degree of convergence between media to the point where studying a single medium in isolation would seem positively reactionary. And it points to the growing opportunities for media production by young people themselves opportunities which much surely be seized by media educators.

Ultimately, there is a widening gap between children's world outside school and the emphases of many education systems. While the social and cultural experiences of children have been dramatically transformed over the past fifty years, schools have signally failed to keep pace with change. The classroom of today would be easily recognizable to the pioneers of public education of the mid-nineteenth century: the ways in which teaching and learning are organized, the kinds of skills and knowledge that are valued in assessment, and good deal of the actual curriculum content, have changed only superficially since that time. Indeed, some have argued that schooling is now heading determinedly backwards, retreating from the uncertainty of contemporary social change towards the apparently comforting stability of a new 'educational fundamentalism', in which traditional relationships of authority between adults and children can be restored (Kenway and Bullens, 2001).

Of course this is not to posit an absolute opposition between 'school cultures'. The school is inevitably a site for negotiation (and often for struggle) between completing conceptions of knowledge and cultural values. Nevertheless, there is now an extraordinary contrast between the high levels of activity and enthusiasm that characterize children's consumer cultures and passivity that increasingly suffuses their schooling. Of course, teachers have perennially complained about children's weakening 'attention span'; although in fact the levels of intense concentration and energy that characterize children playground engagement with phenomena like Pokemon are quite odds with 
the deadening influence of mechanical teaching and testing that currently prevail in many classrooms (Buckingham and SeftonGreen, 2003). Thus, Jane Kenways and Bullen (2001) point out, the 'knowledge politics' of children consumer culture often explicitly oppose those of formal schooling, presenting teachers as dull and earnest, worthy not emulation of well-justified rebellion and rejection. Like a Rabelaisian 'carnival', children's media culture has increasingly become an arena in which authoritarian values of seriousness and conformity are subverted and undermined.

In this context, it is hardly surprising if children perceive schooling as marginal to their identities and concerns or at best as a kind of functional chore. Yet if schools are to engage with children's media culture, it is clearly vital that, in doing so, the do not simply attempt to re-inscribe traditional notions of what counts as valid knowledge. To a much greater than in conventional academics subjects, treachery attempts to imposing cultural, moral or political authority over the media that children experience in their daily lives are very unlikely to be taken seriously. If, as in many cases, they are based on paternalistic contempt for children's tastes and pleasures, they certainly deserve to be rejected. It is for these reasons that protectionist approaches to media education whether cultural, moral or political in nature are at least redundant, if not positively counter-productive.

However, this is not suggested that media education should abandon the project of cultural criticism, or that it should merely celebrate the activity and energy of children's relationships with the media. If it were to exist, such an approach would at best be merely superficial; and at worst, it could be seen to represent a form of complicity with the assertions of children's 'consumer sovereignty' that are so enthusiastically promoted by the media industries. There are significant constraints on children's autonomy as users of media, and on the diversity of their experiences. The media and institutional power; and sometimes contradictory ways in which these operate. Yet if media education is to help bridge the widening gap between the school and 
the world of children's out of school experience, it must surely begin with the knowledge that children already possess.

\subsection{The Implication with Health}

There is growing concern, as in many other countries, about the rise in childhood obesity, and the future implications for the funding of the health service. The fat child has become a new kind of folk devil, a rapacious, insufficiently socialized monster. As is often the case in such debates, commentators tend to blame the media. In fact, there may be many complex reasons for the rise in obesity. One of them may be that the government is so obsessed with pushing up educational standards that it has seriously cut back on the amount of time children spend doing physical education in schools. But - as with violence - blaming the media always provides an easy option, and it gets attention for politicians who need to be seen to be «doing something> about the problem. So there have been mounting calls for the government to regulate the advertising of so-called ¿junk food to children - and some critics point to countries like Sweden, where all advertising aimed at children is banned (at least on terrestrial television). In practical terms, this call to ban such advertising raises some quite difficult questions - not least to do with how you define as junk foods (for example, advertisers are keen to point out that fruit juice is higher in sugar).

They content, and more harmful for teeth, than sugary soda drinks; and they argue that food is only junk when consumed in excess, and to the exclusion of other foods.) Obesity is clearly not only a matter of particular foods, but about overall diet and about levels of activity. As a result, it would be quite difficult for government to provide a clear and sustainable rationale for what is to be banned, and why.However, this debate also raises bigger issues about the influence of advertising. As with the debate about sex and violence in the media, children tend to be defined here as innocents in need of protection - as somehow at risk of being corrupted by the powerful influence of the media. Here we find the classic image of the incompetent child - the child that is too immature, too irrational, too inexperienced, too cog- 
nitively undeveloped, to know what is happening or to be able to resist it. Despite developments in academic research and in the media industries themselves, it is this construction of the child that continues to dominate the public debate about children and the media.

Nevertheless, research on the influence of advertising, and particularly on how people make food choices, suggests that this is a rather more complicated issue. While there is a considerable amount of debate on the matter, many researchers argue that advertising is actually a relatively insignificant influence on food choice, compared with issues such as constand availability and the amount of time people have to cook and go shopping. Indeed, this was broadly the conclusion of Ofcom's own review of research on the matter (Ofcom, 2004). More to the point, research also tends to show that children are well aware of the persuasive intentions of advertising from a relatively young age: again, there is some debate about the matter, but it is generally agreed that by the time they reach the age of eight, most children are capable of mobilizing quite a cynical discourse about advertising (Young, 1990). I have interviewed children who will describe at length and in great detail, and with a good deal of hilarity, how advertisements are full of lies, about how the products they are selling are really rubbish, and about how the claims of advertising are always exaggerated and false (e. g. Buckingham, 1993: Chapter 7).

At least on the face of it, children are very keen to present an image of themselves as entirely competent - as more than able to see through the false claims of advertising, and capable of making rational decisions about what they buy. Of course, one can see why it would be in their interest to do so - not least because they are bound to be aware of the public discourse. Buckingham would also argue that children are less aware of some less visible forms of advertising, such as sponsorship, branding and product placement - let alone the ways in which the internet is used for commercial gain, for example by gathering consumer information (see Seiter, 2004). 


\section{CONCLUSION}

Children as young learners must be protected from the media abused. There are many factors why protecting children as one of the focuses in doing teaching and learning process. Children when they stay at their houses; so the parents must facilitate them with parental guidance while they watching audio-visual (television, video recorder). It is the same when they study at their schools; so that teachers must be responsible too. Children having different their own styles in consuming media as experienced. We should consider to all these dynamics point of view. It is possible to identify two contrasting views of the relationship between children and media, both of which have been influential in popular and academic debate. On the one hand, there is the idea that childhood as we know it is dying or disappearing, and that the media are now a force of deliberation that is more open, more democratic, and socially aware than their parents' generation. In some ways, these two views are diametrically opposed, not least in their underlying assumptions about childhood; yet there are also some striking similarities between them.

Talking about ICT as media education Buckingham said that there are three dimensions consists in the use of media education. Firstly, like many advocates of media education; it is lack of progress we seem to have made among educational policy-makers in recent years. Where students are free to choose it - and teachers free to offer it - media education continues to expand a quite alarming rate. Secondly, among academics there has been a flourishing of esoteric political rhetoric and an increasing taste for utopian fantasies about educational change. The third, there are some fact that teachers of media education still seem to be insufficiently recognized and supported. Despite the generally inhospitable climate, there is a great deal of excellent work being done in the field by highly dedicated teachers and committed students (Tapscott, 1989).

Thus, we have seen a gradual shift away from extended families, and then increasingly to non-traditional family structures of various kinds most notably single-parent families. Buckingham (2008: 21) says children are now much more likely to be confined to their homes, and much less independently mobile, then they were twenty 
years ago; and while parents now spend much less time with their children, they are attempting to compensate for this by devoting increasing economic sources to child-rearing. Meanwhile, there has been a steady extension of the years of compulsory schooling, and of the proposition of young people continuing in post-compulsory education. Increasing numbers of children are also now in preschool education of some kind. On the other hand, youth unemployment is rising, and in some countries state benefits for young people has been withdrawn; and as a result, young people are now becoming increasingly dependent upon their parents. There have also been significantly dependent significant changes in peer group culture. Young people are now having sex earlier than in previous decades; and they are maturing physically at an ever-earlier age. Drugs have become an almost taken-for-granted aspect of young people's recreational experience; and despite the 'war of drugs', drug use is now at higher level than ever before. There is also increasing anxiety about the incident of child crime, although statistically children are much more likely to be victims of crime than other age groups.

As a result of these developments, there have been changes in children's status as a distinctive social group. On the other hand, there is growing concern about the need to protect children, particularly from forms of abuse; on the other, there have been increasingly punitive attempts to deal with a perceived breakdown in discipline. At the same time, the issue of children's right has become much more significant in recent years. Following the UN Convention on the Rights of the Child, many countries have passed new legislation to protect children's right, both in family and in their dealing with state agencies. However, this concern for children's rights goes along with new emphasis on children as a potential market. If capitalism can be said to have created 'the teenager' in the 1950s, children are now increasingly addressed directly as a consumer market in their own right, rather than simply as a means of reaching parents. Nevertheless, over the past two decades, many Western countries have seen an increasing polarization between rich and poor, and the creation of a growing underclass, in which children are disproportionately represented. 


\section{RECOMMEDATION}

In several respects, recent developments in the media could seen reinforce - and to be reinforced by changes in childhood, of the kind identified earlier in this chapter. Both are characterized by a growing sense of instability and insecurity; established distinctions and hierarchies are breaking down, as new cultural form and new identities emerge. In relation the media as in many other areas of social life, previously distinct boundaries between children and adults are disappearing. And yet, it is suggested such boundaries are simultaneously being reinforced or redrawn.

The separation between children's and adults' media worlds is becoming more apparent, although the terms of that separation are changing. Older children can no longer be so easily 'protected' from experiences that are seen to be morally damaging or unsuitable. The walls that surround the garden of childhood have become much easier to cliemb. And yet children particularly younger children are increasing degree of convergence between media to the point where studying a single medium in isolation would seem positively reactionary. And its points to the growing opportunity for media production by young people themselves - opportunities which must surely be seized by media educators.

Ultimately, the analysis suggests that there is a widening gap between children's world outside school and the emphases of much education system. While the social and cultural experiences of children have been dramatically transformed over the past fifty years, schools have signally failed to keep pace with change. The classrooms $f$ today would be easily recognizable to the pioneers of public education of the mid-nineteenth century: the ways in which teaching and learning are organized, the kinds of skills and knowledge that are valued in assessment, and a good deal of the actual curriculum content, have changed only superficially since that time. 


\section{REFERENCES}

Abbot, C (1998). Digital Diversion: Youth Culture in the Age of Multimedia. London: UCL Press

Abrams, M. (1956).Child Audience for Television. Journalism Quarterly 33: 35-41.

Sadiman. (2003: 28). Media Pendidikan: Pengertian pengembangandan Pemanfaatnya.Jakarta: PT. Raja Grafindo Perkasa, 2003), p.28.

Asnawir and Usman. (2002: 29). Media Pemebelajaran. Jakarta: Ciputat Press

Arsyad, Azhar. (2004: 10-11). Media Pembelajaran.Ikapi; Bandung

Bogdan, Robert. C and Biklen, Sari Knopp. (1990). Riset KualitatifUntukPendidikan: Pengantar Teoridan Metode. AlihBahasa: Munandir. Jakarta: Ditjen Dikti Depdikbud

Brown, H. Douglas. (2000). Principles of Learning and Teaching. New York: A Pearson Education Company

Block, L. and Buckingham. (2010: 3). Global Children, Global Media: Migration and Media Childhood.(Pelgrave. MacMillan).

Cresswell, David. (2005: 4). The Methodology of Research. MacMillan

Davies, M. M. (1997). Fact, Fake and Fantasy: Erlbaum

Del Vecchio, G.(1997). A Marketer Guide to a Kid's. Heart. LA: Pelican

Flawell, L. (2009: 4). Investigating the Place of the "T" in ICT in Early Childhood

Education.Oxford University Press. 
Gerlach, R \& Ely. (2008: 12). The Principal of Media Literacy. MacMillan Publisher

George, W. M. (2011: 6). The Elements of Library Research.Princeton Reference.

Hurd, G. and Connell (1989).Cultural Education; a Revised Program. Media Information Australia 53: 23-30

Isaac, Stephen. (1990: 152). Handbook in Research and Evaluation for Educational and Behavior Science. Library of Congress Catalogue

Kenway, J and Bullens, E. (2001).Consuming Children: Education, Entertainment, Advertising. Open University Press

Laybourne, G. (1993). The Nickelodeon Experience.Children and Television. London

Mason, R. (20112: 54). Literacy and Media. MacMillan Publisher

Melody, W. (1973) Children's Television.Yale University Press. Oxford Learner's Pocket Dictionary

Harian Sinar Harapan (15 April 2009)

Tapscott, D. (1998). Teaching Popular Culture: Beyond Radical Pedagogy. London: UCL Press

Tarpley, Todd.(2007:4). The Future of Televisual Media. Lawrence Earlbaum Associates, Inc.

Waltermann, andMachill.(2000). Protecting Our Children on the Internet. Germany:

Foundation

Wikipedia.com

Young, B (1990). Children and Television. Oxford University Press 